\title{
O dicionário como política linguística no contexto do ensino superior
}

\author{
The dictionary as a linguistic policy in the context of \\ higher education.
}

\section{El diccionario como política lingüistica en el contexto de educación superior}

\author{
iD) Ana Luisa Borba Gediel \\ Universidade Federal de Viçosa (UFV), Viçosa, Minas Gerais, Brasil. \\ E-mail: ana.gedielufv@gmail.com \\ iD (9) Cíntia Kelly Inês Freitas \\ Universidade Federal de Viçosa (UFV), Viçosa, Minas Gerais, Brasil. \\ E-mail: cintiakellyifreitas8@gmail.com
}

Resumo: A entrada de pessoas Surdas trouxe mudanças na educação formal e explicitou desafios para gerar a permanência delas no Ensino Superior. Objetivamos analisar as possibilidades de desenvolvimento e uso do Dicionário online bilíngue Libras/Português no cotidiano do ES. A análise foi feita através da perspectiva de alunos Surdos, via Interação Humano-Computador (IHC), combinada à etnografia e observação participante. Discutimos sobre as Políticas Linguísticas e a dicionarização da Libras como uma iniciativa para apoiar o processo de empoderamento linguístico. Os resultados apontaram para a utilização do Dicionário como um repositório de conceitos de áreas cursadas pelos alunos Surdos da IES.

Palavras-chave: Libras. Política Linguística. Dicionário. Acessibilidade. Ensino Superior. 
The entrance of Deaf people brought changes in formal education and demonstrated challenges for their permanence in Higher Education. We objectified to analyze the online bilingual Dictionary in Libras/Portuguese and the possibilities of developments and uses in the higher education. The analysis was made through the perspective of Deaf students, using the Human-Computer Interaction combined with ethnography and participant observation. We discussed Linguistic Policies and Libras' dictionaryization as an initiative to support the linguistic codification process. The results pointed for the Dictionary's uses as a repository of concepts of areas attended by Deaf students from the university.

Key-words: Libras. Linguistic Policies. Dictionary. Accessibility. Higher Education.

El ingreso de personas Sordas a la Educación Superior trajo cambios en la educación formal e hizo explícitos los desafíos para lograr su permanencia. Analizaremos las posibilidades de desarrollo y uso del diccionario en línea Libras/Portugués en la ES. El análisis se realizó desde la perspectiva de los estudiantes Sordos, a través de la Interacción HumanoComputadora, combinada con etnografía y observación participante. Discutimos acerca de las Políticas Lingüísticas y la diccionarización como una iniciativa para apoyar el proceso de empoderamiento lingüístico. Los resultados apuntaron al uso del diccionario como depósito de conceptos de áreas estudiadas por Sordos de la IES.

Palabras-clave: Lengua Brasileña de Senãs. Diccionario. Accesibilidad. Educación Superior.

Submetido em 29 de maio de 2020.

Aceito em 18 de dezembro de 2020.

Publicado em 09 de julho de 2021. 


\section{Introdução}

A formulação de políticas públicas e de ações afirmativas, especificamente no que tange à educação superior, apoiou iniciativas para gerar equidade, dada a histórica exclusão de grupos sociais que não se encaixavam nos padrões socialmente construídos - sejam eles padrões religiosos, de estética, de inserção social, de posicionamento político e poder econômico (DINIZ, 2009). Desse modo, no contexto do Ensino Superior (ES), a entrada de pessoas Surdas trouxe mudanças na educação formal e explicitou grandes desafios para gerar a permanência desses sujeitos no decorrer e conclusão de seus cursos de graduação.

Esses desafios abrangem um conjunto de questões institucionais, metodológicas e de estratégias de ensino. Dentre elas, a carência de conhecimentos e informações em Língua Brasileira de Sinais (Libras) que apoiem as atividades acadêmicas do aluno surdo, a dificuldade dos professores em produzir materiais didáticos acessíveis, o impasse na comunicação entre alunos, aluno surdo e professores, e a complexidade da tradução de conteúdos em áreas específicas (PIMENTA; LIMA; REIS, 2018). Nesse cenário, a situação da evasão escolar foi evidenciada empiricamente: dos seis alunos Surdos ${ }^{1}$ matriculados nos dois campi da instituição estudada, dois evadiram em menos de um ano de permanência.

Em vista disso, identificamos a necessidade da utilização da Libras como língua de instrução dos Surdos. Sendo que esforços precisam ser empreendidos para que essa língua possa corresponder ao nível de demanda do ES, no que tange ao léxico específico dos cursos em que os alunos Surdos estão matriculados. De acordo com Calvet (2007), é necessário equipar a língua, ou seja, fornecer um conjunto de serviços que são necessários para cumprir essa função.

\footnotetext{
1 A utilização dos termos "Surdo e Comunidade Surda" com a primeira letra grafada em letra maiúscula apoia-se na concepção do antropólogo Magnani (2007), que afirma essa diferenciação como demarcação da singularidade identitária e cultural do grupo. Por esse motivo utilizaremos neste trabalho os termos com a primeira letra em caixa alta.
} 
O dicionário como política linguística no contexto do ensino superior

Ana Luisa Borba Gediel • Cíntia Kelly Inês Freitas

O Planejamento Linguístico é visto como as ações para a implementação de uma Política Linguística, assegurando sua aplicação e concretização para o fortalecimento da língua. Após a publicação da Lei 10.436/2002, que reconheceu a Libras como língua proveniente da Comunidade Surda (BRASIL, 2002), houve um crescimento de pesquisas no campo das Línguas de Sinais, além da efetivação de medidas que assegurem o acesso e permanência dos Surdos na educação. Iniciativas de adaptações estruturais e metodológicas começaram a ser desenvolvidas para apoiar a ressignificação das práticas e, também, para proporcionar oportunidades de formação discente e docente (LOPES; FERNANDES, 2017).

Neste trabalho, discutiremos as ações voltadas especificamente para a implementação do Dicionário online bilíngue Libras/Português ${ }^{2}$ como parte de uma Política Linguística (PL), que emerge a partir da identificação de problemas locais envolvendo a Libras e seus usuários. Foi realizada a identificação de grandes barreiras comunicacionais entre Surdos e ouvintes nos diversos ambientes educacionais da IES que se constituiu como o campo desta pesquisa. Portanto, nosso trabalho engloba o desenvolvimento do Dicionário para atender às demandas de Surdos e Tradutores e Intérpretes de Libras/Português (TILSP), no que se refere à carência de léxico específico ${ }^{3}$ no ES.

Levamos em consideração as noções evidenciadas por Louis-Jean Calvet (2007), de que a formulação das PL e o planejamento linguístico surgem a partir da identificação de desafios que se relacionam com a estruturação da língua e o seu uso. Sendo assim, a partir de uma perspectiva teórica, torna-se mais viável a elaboração de intervenções, o estudo da sua eficácia, as formas de implementá-las e de avaliá-las. Calvet (2007) reitera a necessidade de equipar a língua para que ela seja utilizada como a língua de ins-

\footnotetext{
2 Dois órgãos governamentais de fomento viabilizaram as pesquisas e o desenvolvimento do Dicionário: 1) a Coordenação de Aperfeiçoamento Pessoal a Nível Superior - CAPES -, por meio do Edital Capes Inovação 2015, vinculado ao sistema Universidade Aberta do Brasil (UAB) que possibilitou a criação do software, e 2) o Conselho Nacional de Desenvolvimento Científico e Tecnológico - CNPq -, por meio de bolsa de iniciação científica que gerou os dados aqui apresentados.

3 A elaboração de materiais focados em sinais de áreas específicas são fundamentados nas teorias da Lexicografia da Libras, que vem sendo realizados em diferentes Universidades no Brasil. A partir das colocações de Faulstich (2014), entendemos que esses estudos buscam a relação signo, significado e significantes na Libras para que assim se desenvolvam sinalários, glossários e dicionários.
} 
O dicionário como política linguística no contexto do ensino superior

Ana Luisa Borba Gediel • Cíntia Kelly Inês Freitas

trução, sendo a criação de Dicionários terminológicos um recurso amplamente utilizado no processo de consolidação de uma língua.

O objetivo deste artigo é, portanto, analisar as possibilidades de uso e os desafios de desenvolvimento dessa ferramenta para a aplicabilidade no cotidiano do ES, a partir da perspectiva dos próprios alunos Surdos. Além disso, busca-se através desta investida atender aos interesses dos agentes Surdos por meio da utilização do Dicionário como apoio para a comunicação nas mais diversas esferas sociais. É uma forma de instrumentalizar uma língua que durante séculos era tida como inferior às línguas orais e considerada como um empecilho para o desenvolvimento da oralização pelos Surdos (MEDEIRO; VIVEIROS, 2017).

O percurso metodológico foi baseado nos preceitos etnográficos, com a observação participante, notas de campo e diário de campo (OLIVEIRA, 1996). Usufruímos, ainda, da Interação Humano-Computador (IHC) a partir da experimentação (fase-teste) para analisarmos o potencial da ferramenta (BARANAUSKAS, 2003). Nos centramos nas análises das contribuições de três alunos Surdos regularmente matriculados na IES na ocasião de realização da pesquisa.

Neste artigo, inicialmente tecemos uma discussão acerca das PL partindo de uma perspectiva geral para, em seguida, focalizarmos as ações desenvolvidas no contexto estudado. Logo, apresentaremos a proposta de criação do Dicionário4 Bilíngue online Libras/Língua Portuguesa na IES pesquisada e como essa iniciativa se insere no campo da Linguística das Línguas de Sinais. Posteriormente, demonstraremos o percurso metodológico para levantamento dos dados, o contexto da pesquisa, os instrumentos de coleta de dados, o perfil dos colaboradores da pesquisa e a análise dos dados.

\footnotetext{
40 Dicionário é resultado de concepções e pesquisas traçadas por meio de um projeto institucional desenvolvido em uma Instituição de Ensino Superior (IES) do interior de Minas Gerais, Brasil. Este projeto é constituído por uma equipe interdisciplinar, que envolve discentes e docentes dos Departamentos de Letras, Ciências Sociais, Educação e Biologia Geral em parceria com o Centro de Educação Aberta e a Distância da IES.
} 


\section{O desenvolvimento de políticas linguísticas para o reconhecimento da libras como língua de instrução no contexto do ensino superior}

A trajetória de reconhecimento da Libras como língua não se restringe às disposições legais. No contexto de convívio social, em que a comunicação e a expressão se estabelecem, é crucial a promoção de ações que minimizem a sobreposição do Português em relação a Libras. Esse cenário supressor vem sendo sustentado pela crença de que a Libras não possibilita uma comunicação efetiva e tampouco a expressão de conceitos abstratos (GESSER, 2009).

A partir das mobilizações de teóricos, de pesquisadores e de falantes nativos da língua, esse cenário vem sendo modificado gradualmente (SOFIATO; REILY, 2014). Contudo, algumas problemáticas ainda são recorrentes: a falta de terminologias em áreas específicas, a não padronização da língua, a escassez de capacitação e da formação de profissionais que atuam na área.

Formular e implementar uma PL que vise a reduzir essas lacunas requer um esforço colaborativo entre alunos Surdos, linguistas, TILSP e professores. É preciso atentar-se para a compreensão de como as práticas de uso da linguagem acontecem, assim como para o reconhecimento dos encaminhamentos e de suas implicações nas comunidades que as investigam (SOUZA; SOARES, 2014).

Esses fatores geram grandes desafios no processo interpretativo em sala de aula, já que os agentes envolvidos no contexto educacional - professor, aluno surdo e TILSP - estão em processo de reconhecimento dos papéis a serem desempenhados. Nessa situação, os conceitos de áreas específicas ainda estão sendo investigados e catalogados para gerar sinais-termos (FAULSTICH, 2014).

Por conseguinte, o profissional TILSP nem sempre possui o acesso ao conteúdo previamente elaborado pelo professor para estudar possíveis traduções para o uso de sinônimos ou classificadores (PIMENTA; LIMA; REIS, 2018). Desse modo, de acordo com 
O dicionário como política linguística no contexto do ensino superior Ana Luisa Borba Gediel • Cíntia Kelly Inês Freitas

as autoras, para minimizar esses desafios os TILSP valem-se de observações prévias das aulas para obter a compreensão dos conceitos, evitando o uso excessivo da datilologia e a incompreensão na sinalização. Em consequência desse panorama, os alunos Surdos acabam distanciando-se, muitas vezes, dos conhecimentos ministrados em sala de aula.

Ações apoiadas no desenvolvimento de um arcabouço lexical buscam gerar acessibilidade dos Surdos na apreensão de conhecimentos científicos em áreas específicas. A criação de dicionários, glossários, vocabulários de áreas tecnológicas e a verificação da autenticidade de sinais-termos utilizados no processo de tradução especializada vislumbram minimizar os impasses linguísticos de comunicação (FELTEN; FAULSTICH, 2013). Tais discussões alinham-se aos pressupostos bilíngues/biculturais ${ }^{5}$ (MENGALE, 2018). E, ainda, vai ao encontro da perspectiva da aquisição da língua de sinais priorizada como a língua materna/primeira língua (L1), sendo esta considerada a língua natural aos Surdos, e o português como segunda língua (L2) (QUADROS, 1997).

A Libras passa a ser adotada como língua de instrução e mediadora das trocas no contexto educacional. Esse processo de empoderamento da língua por seus usuários pode ser estabelecido através de um sistema de escrita, com foco em um sistema de transcrição ou um alfabeto por exemplo. Por se tratar de uma língua em ascensão, a criação de dicionários é uma prática emancipatória, que ao se estabelecer cumpre a finalidade de oferecer um material de apoio ao professor e um material de consulta ao aluno (SOFIATO; REILY, 2014). Após os estudos de elaboração da iniciativa é necessário divulgá-la para que haja uma implementação efetiva (CALVET, 2007).

Para esse tipo de criação é necessário que os planejamentos sejam protagonizados por grupos que possuem autoridade e legitimidade para dispor sobre a língua e seus usos. Considerando essa premissa, observamos a colaboração de profissionais TILSP,

5 Entendemos, a partir da perspectiva de Mengale (2018, p. 12), que os sujeitos bilíngues biculturais são aqueles que conseguem reunir "as características culturais do universo de falantes da sua segunda língua às características tidas como próprias de sua cultura de origem". 
técnicos, professores e alunos Surdos e ouvintes que estão inseridos na Comunidade Surda para o desenvolvimento de ações na instituição investigada. Esses agentes se empenham para "estabilizar" a Libras como língua de instrução (CALVET, 2007). Estas exploram os recursos linguísticos da Libras para a explicação de teorias específicas, como mapeamento e catalogação de sinais de áreas específicas para a constituição de sinalários.

Como pontuado por Cáceres (2014), os planejamentos realizados por grupos que possuem autoridade e legitimidade para dispor sobre a língua e seus usos o fazem para alcançar o objetivo demandado pelos usuários da língua. De maneira equivalente, os usuários da Libras que compõem instituições de ensino e outras organizações são agentes importantes para a formulação e caracterização das $\mathrm{PL}$, uma vez que esses podem apontar modificações necessárias de acordo com o perfil e a cultura dos falantes.

Finalmente, por meio das considerações trazidas, compreendemos que a criação do Dicionário como uma PL contribui para o reconhecimento da Libras como língua de instrução no contexto do ES. Sendo esta uma língua oriunda da Comunidade Surda, verificou-se que a ação voltada para a implementação da ferramenta tem relação direta com os interesses do grupo.

\section{A proposta de criação do dicionário online bilíngue libras/ português}

Com o reconhecimento da Libras como língua da Comunidade Surda, por meio da Lei n 10.436, de 24 de abril de 2002, a criação de Dicionários digitais vem crescendo progressivamente no Brasil (SOFIATO; REILY, 2014). Os dicionários impressos são os gêneros comumente encontrados, porém, ao se tratar de uma língua de modalidade espaço-visual, o uso de imagens estáticas por vezes não atende à necessidade de apreensão de um sinal. Então, é nesse sentido que a produção de dicionários online vem ganhando espaço entre a Comunidade Surda e os demais aprendizes da língua. 
O dicionário como política linguística no contexto do ensino superior Ana Luisa Borba Gediel • Cíntia Kelly Inês Freitas

Ancoradas na perspectiva de divulgação das iniciativas de fortalecimento linguístico de Calvet (2007), apresentamos as características e o processo de desenvolvimento do Dicionário Online Bilíngue Libras/Língua Portuguesa. O Dicionário é um software acessado por meio do link correspondente ao endereço https:// sistemas.cead.ufv.br/capes/dicionario/, podendo ser utilizado através de computadores e smartphones. Para além dos sinais dispostos dentre os conteúdos do Dicionário, encontramos: frases de aplicação dos sinais em português e em glosas ${ }^{6}$, vídeos de aplicação das frases de exemplo, recurso de busca por configurações de mão, busca por temas, barra de pesquisa por palavras e histórico de busca.

O objetivo do Dicionário é auxiliar no processo comunicacional entre Surdos e ouvintes professores, estudantes, monitores de disciplinas, bem como auxiliar o trabalho dos TILSP que interagem nos diferentes ambientes de ensino e aprendizagem da IES. Abaixo são apresentadas as descrições dos ambientes da ferramenta e suas respectivas ilustrações.

Ao acessar, visualizamos na página inicial ao centro um vídeo sinalizado com legendas em português, em que o Dicionário é apresentado de forma breve. No lado esquerdo da tela, há uma barra de pesquisa onde são inseridas as palavras em português para a busca do sinal. Abaixo da barra de pesquisa, encontram-se os temas disponíveis para consulta no Dicionário, sendo assim, não é necessária a busca apenas pela palavra em português, pois é possível encontrar a palavra desejada a partir do tema em que está agrupada. Todas essas funções estão ilustradas na imagem que segue.

6 As glosas foram definidas por Paiva et al. (2016), como palavras de língua oral grafadas com letra maiúscula representando sentido aproximado com sinais da língua espaço-visual. 
O dicionário como política linguística no contexto do ensino superior Ana Luisa Borba Gediel • Cíntia Kelly Inês Freitas

\section{Figura 1 - Página inicial de verbetes do Dicionário Online bilíngue Libras/ Português parte superior}

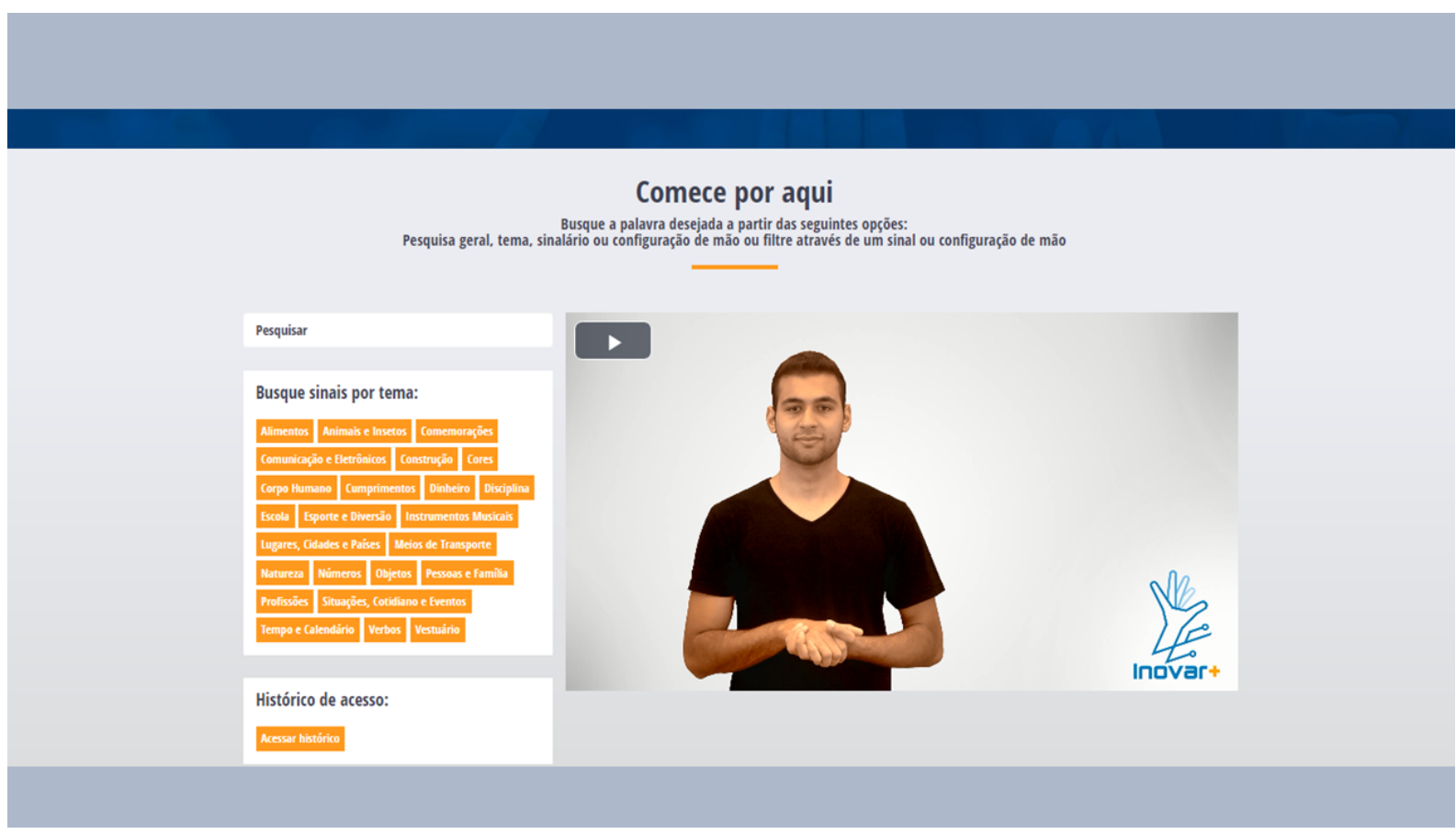

Fonte: Dicionário Online bilíngue Libras/Português (2020)

O Dicionário também possui o recurso de busca por configuração de mão ${ }^{7}$ na parte inferior da tela, correspondente a um dos cinco parâmetros fonológicos da Libras. A busca por configuração de mão é um dos aspectos que contribuem para a característica bilíngue do Dicionário, uma vez que usuários que não fazem uso confortável do português podem utilizar o recurso para pesquisar os sinais desejados. Os ícones de cada uma das configurações de mão podem ser visualizadas na imagem abaixo:

7 Configuração de Mãos (CM) é um dos parâmetros gramaticais da Língua Brasileira de Sinais. Representa a primeira configuração que a mão se encontra antecedendo os movimentos da sinalização (QUADROS; KARNOPP, 2004). 
O dicionário como política linguística no contexto do ensino superior Ana Luisa Borba Gediel • Cíntia Kelly Inês Freitas

Figura 2 - Página inicial de verbetes do Dicionário Online bilíngue Libras/ Português parte inferior

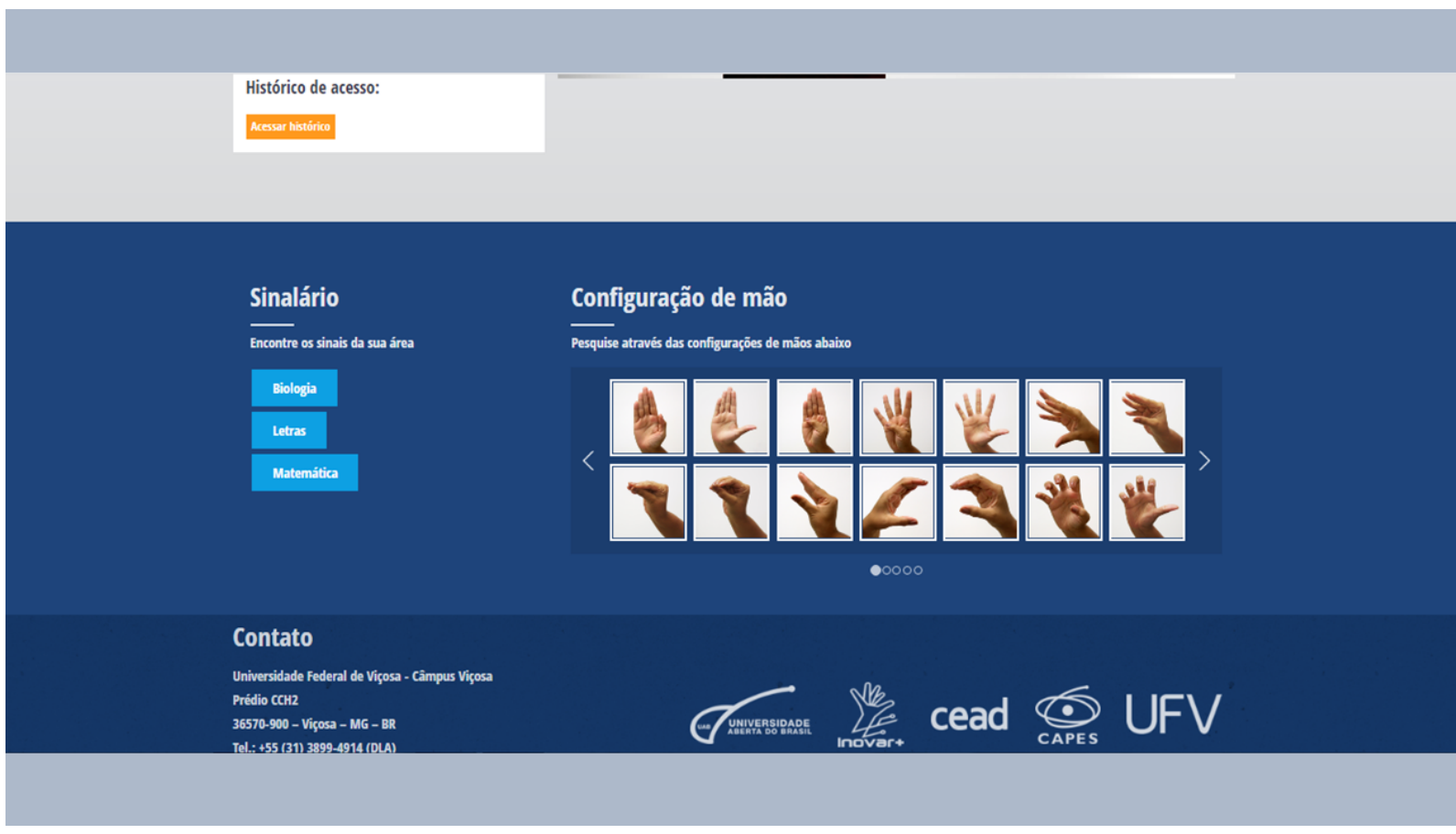

Fonte: Dicionário Online bilíngue Libras/Português (2020).

Por ser um Dicionário voltado principalmente para o contexto do ES, o recurso de busca por sinalário de áreas específicas do conhecimento tem sido o alvo das atuais pesquisas de desenvolvimento do software. Atualmente, o Dicionário contém sinais básicos de apenas três áreas: Biologia, Letras e Matemática, porém, a partir das pesquisas realizadas pelo projeto fomentador, planeja-se ampliar os sinais desses conteúdos e adicionar temas de outras áreas do conhecimento. A equipe envolvida na criação e aperfeiçoamento do Dicionário é composta por profissionais TILSP, discentes e docentes surdos e ouvintes dos Departamentos de Letras, Ciências Sociais, Educação e Biologia Geral e Técnicos com formações na área de Libras e Informática, envolvendo integrantes Surdos em diferentes instâncias.

Em relação à busca a partir do ícone "pesquisa", no lado superior esquerdo sobressai a palavra procurada e no centro da página aparecerá a execução do vídeo do sinal correspondente. Será 
O dicionário como política linguística no contexto do ensino superior Ana Luisa Borba Gediel • Cíntia Kelly Inês Freitas

identificada, ainda, a aplicação dessa palavra em uma frase em português, em glosa simplificada ${ }^{8}$ e a configuração de mão referente ao sinal. As páginas de verbetes são como indicadas na foto abaixo:

\section{Imagem 3 - Página dos verbetes Dicionário Online bilíngue Libras/Português}

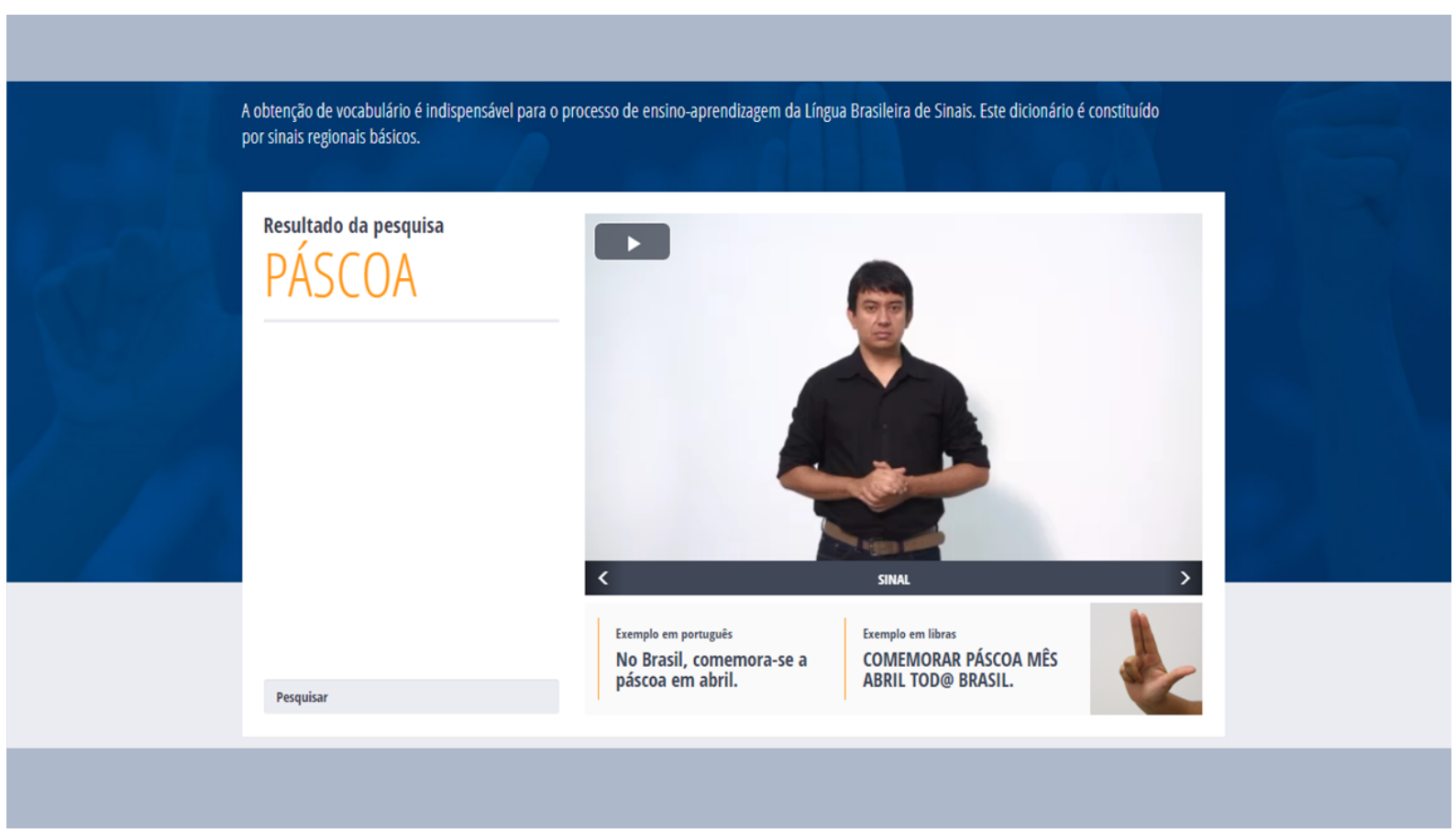

Fonte: Dicionário Online bilíngue Libras/Português (2020)

O Dicionário está em processo de desenvolvimento, ainda com uma pequena quantidade de sinais adicionados, em razão do extenso processo de catalogação, correção, gravação, revisão e inserção dos sinais no software por Surdos ${ }^{9}$ e ouvintes. Além disso, a partir dos testes, existem diversos apontamentos de funções a serem modificadas e efetivadas nos próximos anos.

O desenvolvimento de dicionários precisa seguir critérios que possibilitem uma reprodução dos sinais de forma mais fiel possí-

\footnotetext{
8 No Dicionário, consideramos que os textos que estão representados em formato de glosa são simplificados, visto que não utilizamos todos os componentes gramaticais que as constituem. Glosas são "palavras de uma determinada língua oral grafadas com letras maiúsculas que representam sinais manuais de sentido próximo". (PAIVA et al., 2016, p.13).

90 processo de criação do Dicionário envolveu profissionais e alunos Surdos e ouvintes, sendo que a criação dos exemplos de aplicação dos sinais e a gravação do conteúdo têm a preeminência dos Surdos. Desse modo, a participação dos Surdos não ficou restrita à análise da ferramenta.
} 
O dicionário como política linguística no contexto do ensino superior Ana Luisa Borba Gediel • Cíntia Kelly Inês Freitas

vel, a fim de facilitar a apreensão do conteúdo. Esse objetivo pode ser alcançado através da participação de Surdos como protagonistas dos conteúdos dos glossários (SOFIATO; REILY, 2014, p. 117). Sendo assim, a produção do Dicionário de Libras é um desafio enfrentado para contribuir para uma educação de qualidade para os Surdos.

\section{Os passos metodológicos para levantamento dos dados}

Apresentaremos aqui uma discussão teórica e empírica sobre o processo de avaliação do Dicionário por três estudantes Surdos ${ }^{10}$ regularmente matriculados na IES. A participação desses alunos ocorreu através do teste de usabilidade ${ }^{11}$, sendo a observação participante e a análise da Interação Humano Computador (IHC) as ferramentas de verificação das categorias.

A metodologia também foi baseada nos preceitos etnográficos, como observação participante, notas de campo e diário de pesquisa (OLIVEIRA, 1996), visto que o contexto do campo extrapolou a realização dos testes, tendo o acompanhamento prévio dos alunos, conversas em diferentes locais da instituição e registros de notas baseadas nas interações anteriores e posteriores ao teste.

Foi realizado um teste de uso do Dicionário em um laboratório de informática na IES no ano de 2018, em que todos os participantes tiveram as mesmas condições estruturais de uso. Porém, cada teste foi realizado separadamente, em horários diferentes. Os usuários já possuíam contato com os componentes da equipe e também tinham familiaridade com o local de realização da atividade, o que favoreceu a participação de forma mais fluída.

Para a autorização dos colaboradores, foi realizado previamente o processo de registro do projeto, identificando os riscos

\footnotetext{
10 Em determinados momentos serão denominados "usuários", por ser um termo comumente utilizado nas teóricas de análise da Interação Humano-Computador (IHC).

11 A usabilidade de uma ferramenta é avaliada como o grau de facilidade de aprendizado, a eficiência de seu uso, o grau de lembrança do usuário sobre usos específicos e a facilidade de assimilação das informações disponíveis.
} 
e benefícios, com a autorização dos chefes dos centros de ciências. Esse procedimento ocorreu com autorização de uso de imagem, observação e filmagem, de acordo com a permissão emitida no parecer do Comitê de Ética em Pesquisa com Seres Humanos (CEP) da IES, tendo como código 2.538.160.

Para a apresentação dos participantes da pesquisa foi elaborado um quadro contendo a identificação, o tempo do teste e a representação de um breve perfil, apresentando os conhecimentos linguísticos autodeclarados e as principais características do desempenho na utilização da ferramenta. Na coluna de identificação, os colaboradores são referenciados a partir da Configuração de Mão (CM) de seu sinal, que está representada por figuras e tem como objetivo resguardar a identidade dos participantes da pesquisa. O tempo de duração e as dificuldades percebidas não foram descartadas da análise dos dados, pois essas questões também nos apontam categorias importantes para o estudo, como o grau de facilidade de manuseio do Dicionário.

O quadro abaixo apresenta os colaboradores da pesquisa seguindo o padrão utilizado por Gediel (2010):

Quadro 1 - Perfil dos colaboradores da pesquisa

\begin{tabular}{|c|l|c|}
\hline Identificação & Perfil & $\begin{array}{l}\text { Duração do } \\
\text { teste }\end{array}$ \\
\hline & $\begin{array}{l}\text { Estudante de graduação na IES. Conhecimento em Libras e } \\
\text { Lingua Portuguesa, dificuldade média de manuseio da } \\
\text { ferramenta e entendimento dos comandos do teste. }\end{array}$ & 57 min e 1s \\
\hline & $\begin{array}{l}\text { Estudante de graduação na IES. Conhecimento em Libras e } \\
\text { Língua Portuguesa, facilidade em manusear a ferramenta e } \\
\text { fácil entendimento dos comandos do teste. }\end{array}$ & $\begin{array}{r}57 \mathrm{~min} \\
28 \mathrm{~s}\end{array}$ \\
\hline & $\begin{array}{l}\text { Estudante de graduação da IES. Conhecimento em Libras e } \\
\text { Língua Portuguesa, facilidade em manusear a ferramenta e } \\
\text { fácil entendimento dos comandos do teste. }\end{array}$ & $\begin{array}{l}38 \mathrm{~min} \\
68 \mathrm{~s}\end{array}$ \\
\hline
\end{tabular}

Fonte: Gediel e Freitas (2019). 
O dicionário como política linguística no contexto do ensino superior Ana Luisa Borba Gediel • Cíntia Kelly Inês Freitas

Para a aplicação do teste foi previamente elaborado um roteiro em Libras e em Língua Portuguesa para apoiar os participantes. Além disso, a equipe que participou do desenvolvimento do teste foi composta por dois TILSP vinculados ao projeto, quatro pesquisadores e uma técnica em informática. O roteiro foi estruturado em glosa simplificada, processo que consiste na criação de frases a partir da sinalização, considerando o contexto e o sentido das palavras de acordo com a estrutura da Libras (PAIVA et al., 2016). Para a exemplificação desse roteiro apresentamos o quadro a seguir:

\section{Quadro 2 - Conversão de frases do português para glosa simples}

\begin{tabular}{|l|l|}
\hline FRASE EM PORTUGUÊS & FRASE EM GLOSA SIMPLES \\
\hline 1. Ao entrar no site, o que você percebe? & 1. ENTRAR SITE. VOCÊ PERCEBER O QUE? \\
\hline $\begin{array}{l}\text { 2. Clique em cores, e depois procure pelos si- } \\
\text { nais de azul, vermelho e branco. }\end{array}$ & $\begin{array}{l}\text { 2. CLICAR “CORES", DEPOIS PROCURAR SINAL } \\
\text { AZUL, VERMELHO, BRANCO. }\end{array}$ \\
\hline $\begin{array}{l}\text { 3. Pesquise uma Configuração de Mão, depois } \\
\text { escolha } 2 \text { sinais correspondentes a ela. }\end{array}$ & $\begin{array}{l}\text { 3. PESQUISAR UMA CONFIGURAÇÃO DE MÃO, } \\
\text { DEPOIS VOCÊ ESCOLHER 2 SINAIS. }\end{array}$ \\
\hline
\end{tabular}

Fonte: Gediel e Freitas (2019).

As três frases apresentadas são breves exemplos dentre os quinze passos que os usuários tiveram acesso para cumprir o teste. Elas foram entregues em uma folha impressa e interpretadas pelo TILSP que descreveu todo o processo de realização do teste, com o intuito de que a comunicação acontecesse primordialmente em Libras. O roteiro propôs tarefas que levaram o usuário a explorar recursos na ferramenta que são primordiais para a verificação das hipóteses estabelecidas.

Estando os colaboradores de posse do roteiro de teste, o intérprete contextualizou cada passo, trazendo exemplos de como era possível aplicar a ferramenta em situações reais. Ao mesmo tempo, o aluno Surdo tinha condições de ir testando no computador a ação descrita no roteiro. Os usuários realizaram o teste demonstrando facilidade no entendimento do roteiro e utilizando 
O dicionário como política linguística no contexto do ensino superior

Ana Luisa Borba Gediel • Cíntia Kelly Inês Freitas

com tranquilidade o tempo posterior à conclusão dos passos para fazer considerações ${ }^{12}$ sobre o uso do Dicionário.

Para a análise dessa interação optamos pela IHC, a partir da experimentação (fase-teste) que analisa o protótipo ${ }^{13}$ (BARANAUSKAS, 2003). A IHC é analisada através de ferramentas computacionais como aplicativos de gravação de imagem e voz ${ }^{14}$, em combinação com a pesquisa qualitativa (BARANAUSKAS, 2003). O objetivo da análise a partir da observação dos testes de usabilidade é investigar e identificar possíveis falhas para a melhoria e adequação à realidade dos usuários.

Todos os usuários emitiram opiniões positivas quando indagados sobre a potencialidade do Dicionário no processo comunicacional entre Surdos e ouvintes, porém apenas um dos participantes se absteve dos comentários finais por ter deixado o laboratório logo após a conclusão do teste por motivos de saúde.

A análise foi estabelecida a partir da exploração pelo aluno Surdo das funcionalidades que o produto oferece, para gerar entendimento em relação à satisfação do usuário. Sendo assim, as formas como os usuários interagiram e reagiram aos comandos oferecidos mostraram o que é necessário para a adequação da ferramenta às especificidades e demandas (PEREIRA, 2011). Foram observadas variáveis como o desempenho da ferramenta na execução de tarefas em um período de tempo específico, o grau de lembrança que o usuário possui após um período sem fazer uso da ferramenta, as ações e reações emocionais do usuário ao usar o software, a facilidade de assimilação do layout da ferramenta e as considerações gerais de cada usuário. Na organização prevista pelos preceitos da IHC foi possível tornar a avaliação do Dicionário mais próxima aos objetivos traçados.

\footnotetext{
12 As falas dos colaboradores foram transcritas e apresentadas seguindo a versão oral feita pelo TILSP no momento do teste. 13 Protótipo é a versão primeira de um sistema, que é disponibilizada para uso em um período de teste. Esta etapa tem como objetivo amenizar contradições entre o produto e os usuários, reduzindo os riscos e apresentando as mudanças necessárias (SANTOS, 2004).

14 Para isso, foram utilizadas 2 câmeras para registrar o uso da ferramenta, a interação que ocorreu no espaço entre os observadores e os colaboradores, bem como a interação pós teste.
} 


\title{
Os processos de utilização e avaliação do dicionário pelos estudantes surdos
}

Como discussão dos dados encontrados, apresentamos alguns excertos dos testes e a análise sobre eles desenvolvida. As considerações dos interlocutores Surdos em relação à ferramenta são pontuais para a discussão que aqui nos propomos.

A avaliação do Dicionário pelos estudantes Surdos foi primordial para o desenvolvimento e para melhoria da ferramenta, com a análise de sua possível implementação. Essa tarefa dialoga com as teorizações feitas por Louis-Jean Calvet (2007) sobre as PL. O autor descreve que o surgimento do conceito "planejamento linguístico" vem de estudos sobre problemas linguísticos que levaram à necessidade de afastamento de imposições autoritárias sobre a língua.

Um aspecto marcante nas falas dos usuários a importância de que o conteúdo do Dicionário tenha sempre a Libras com maior evidência. Segue um trecho da fala de
reafirma:

\begin{abstract}
“Um bom ambiente, mas falta colocar caixas explicativas em Libras para ficar claro o que significa cada ferramenta de busca. Explicação do que é as frases em glosa em vídeo e não apenas escrito, acompanhadas do significado desse recurso para que os Surdos aprendizes da língua aprendam sobre os recursos linguísticos da Libras. Frases em glosa menos complexas, e contextualizadas e com mais sentido".
\end{abstract}

Tendo em vista a colocação de percebemos que tão importante quanto um layout que diminua o tempo médio de resposta dos comandos pesquisados, é necessário permitir que os usuários tenham autonomia para seguir seu ritmo de aprendizagem (RODRIGUES, 2017). Isso implica na autonomia de uso linguís- 
tico, ou seja, na viabilidade de busca por meio da Libras a partir do acréscimo de caixas explicativas sinalizadas em cada um dos ícones.

As considerações dos estudantes Surdos sobre o Dicionário se configuram como um tipo de avaliação importante no desenvolvimento e aplicação da ferramenta. Pois, como afirma Rajagopalan (2013), as PL não se limitam aos aparatos legais que dispõem sobre uma língua e seus usuários: elas estão relacionadas às ações que envolvam a valorização, a divulgação e o fortalecimento da língua e da identidade de seus usuários.

Em alguns momentos os comentários eram feitos durante os testes, permitindo, assim, a identificação dos obstáculos mais frequentes. Na busca por temas, o impasse dos interlocutores foi no momento de avaliar a forma como os sinais estão agrupados na aba "temas" do Dicionário, considerando que para esse aspecto a subjetividade do usuário influencia na percepção da ferramenta e na organização de seus temas de busca.

Ao propor atividades de busca por temas, alguns termos foram recorrentemente buscados em abas que não correspondiam às palavras que estavam sendo requeridas. Observamos que não houve um consenso avaliativo em relação às palavras e sua inserção em apenas uma aba de um determinado tema. Isto é, a palavra poderia estar alocada em diferentes temas. Esse foi o caso da palavra PROFESSOR, que foi buscada pelos colaboradores nos temas PROFISSÕES e ESCOLA.

No momento de verificação do sinalário, o participante apontou a potencialidade do Dicionário e a possibilidade de expansão do conteúdo, organização das informações e a importância da divulgação da ferramenta:

“É importante inserir os sinais numéricos também. Uma coisa importante é adicionar as áreas de Humanas, Exatas por exemplo e dentro delas colocar as subáreas com os sinais. Eu tenho os sinais de matemática e posso contribuir. Tem muita palavra 
junto, confuso. A busca por configuração de mão é muito legal. Uma sugestão é disponibilizar um link no site para acessar o Dicionário".

O participante descreve a necessidade de ampliação das áreas de conhecimentos incluídas até então na ferramenta, que conta com conteúdos básicos referentes às disciplinas de Biologia, Matemática e Letras. Compreendemos, a partir disso, que os sinais disponíveis não são suficientes para subsidiar a tradução de uma disciplina no contexto do ES. Assim, como aponta Lopes e Fernandes (2017), muitos dos sinais utilizados para veicular o conteúdo em sala nos processos tradutórios são combinados entre os alunos e TILSP, de acordo com o contexto de aplicação do conteúdo. Após esse retorno, a equipe do projeto voltou à catalogação de sinais das áreas já inicialmente elaboradas para continuidade de sua ampliação.

Outra perspectiva que pode ser observada na consideração feita pelo colaborador diz respeito à demanda para o desenvolvimento de estudos lexicográficos. Faulstich (2014) explica que o objetivo da lexicografia é a criação e catalogação de sinais-termos de forma cabível para sua divulgação. A autora descreve que a partir do entendimento do conceito para a formulação - pelos Surdos , o processo de criação do sinal em Libras deve ser feito com uma representação clara do termo, que expresse de forma mais visual possível o conceito. Posterior a esse passo de elaboração da explicação de seu conceito e aplicação, cabe à Comunidade Surda aceitar ou não o sinal criado, podendo implementá-lo ou rechaçá-lo. Em seguida, após a validação do sinal-termo, cria-se plataformas para divulgação. Assim como mencionado por Sofiato e Reily (2014), plataformas como sinalários e dicionários onlines bilíngues são utilizados para agregar e divulgar os sinais criados.

Durante a realização do teste, $\$$ comenta que é comum disciplinas em que não há conhecimento e/ou acesso a sinais já convencionados academicamente e legitimados pelas Comunidades Surdas. Faulstich (2014) afirma que diante desses problemas 
linguísticos e de comunicação, o desenvolvimento de estudos lexicais e terminológicos contribuem para o preenchimento dessa lacuna. Nesse sentido,

“Por exemplo, eu sou da Engenharia Civil, então a minha área é a das exatas. Por exemplo, eu vou explicar algum conceito, ao explicá-lo não posso usar qualquer sinal. Qualquer um não pode, tem que pesquisar o sinal. E o Surdo precisa olhar pra ver se está okay".

Reiteramos a afirmação de Sofiato e Reily (2014), da demanda de planejamento prévio para a criação de sinais-termos. As autoras ainda destacam, conforme mencionamos anteriormente, que os falantes nativos da Libras possuem aval e legitimidade para refletir sobre os conceitos e suas representações. Durante as observações realizadas percebemos a credibilidade dada pelos participantes da pesquisa em relação ao formato do Dicionário. Todos expressaram o reconhecimento da participação ativa de Surdos como protagonistas durante todo o processo de planejamento, criação e execução. Segundo Perlin (2005), é necessário compreender a diferença cultural entre o olhar Surdo e o olhar ouvinte, sendo identificados como peças fundamentais para a produção de materiais didáticos para o ensino e aprendizagem de Libras envolvendo os Surdos.

Por isso, o contato e a participação da Comunidade Surda do processo de criação até o momento de avaliação da ferramenta foi importante para cumprir com o objetivo de divulgação e ensino da Libras. Para que não haja, assim, repetição do quadro histórico de produção de intervenções "para" os Surdos e não "com" os Surdos (SASSAKI, 2007).

O último momento de realização do teste foi direcionado para a apresentação das considerações que os alunos Surdos tiveram em relação ao Dicionário, cia da iniciativa da criação de um Dicionário que valoriza a Libras como a língua principal. Essa ponderação vai ao encontro dos es- 
tudos voltados à educação bilíngue para os Surdos, que significa, dentre outros fatores, considerar a importância política, social e cultural da Libras e de seus usuários (QUADROS, 2005). Dentro dessa perspectiva bilíngue - a qual e e ideais de desenvolvimento do software baseiam-se na adição linguística (para Surdos: Libras como L1 e Português como L2). Isso expressa, como afirma Quadros (2005), entender que o uso da Libras não remete ao não uso do português, mas à ampliação do conhecimento social, cultural e político.

A resposta da ferramenta na execução de tarefas no período de tempo específico para cada usuário foi adequada, o grau de lembrança que o usuário possuiu após um período sem fazer uso da ferramenta mostrou que depois de assimilado, o layout torna-se intuitivo. Os pontos a serem melhorados na utilização do software visam à construção futura de um manual prático de funcionamento, sendo este em Libras, de fácil acesso a toda a Comunidade Surda.

\section{Considerações finais}

A pesquisa cumpriu o objetivo de construir um diagnóstico apurado sobre a utilização do Dicionário a partir dos testes de interface com os alunos Surdos da IES. Dentro das ambições iniciais foi possível realizar, em trabalho colaborativo envolvendo uma equipe técnica e uma equipe de pesquisa, o aprimoramento inicial do Dicionário, que facilitou a implementação da ferramenta em contexto pedagógico na IES.

As possibilidades de uso e os desafios de desenvolvimento da ferramenta foram pontuados na perspectiva dos próprios Surdos. Desse modo, relacionamos tal ação às $\mathrm{PL}$ e situamos alguns aspectos destacados que nos geram desafios para o segmento de pesquisas e atividades para melhorias do Dicionário. 
Consideramos, a partir de então, que o Dicionário é acessível para os Surdos, mas que ainda há um longo caminho a ser percorrido para ampliar a tradução dos conteúdos apresentados nos comandos da ferramenta para a Libras. Pontuamos também que as configurações de mãos e os vídeos em Libras auxiliaram a compreensão dos colaboradores durante as buscas por determinadas palavras em Língua Portuguesa. Desse modo, o mecanismo de busca das configurações é inovador e diferente daqueles existentes em outros dicionários da área.

Outra alteração feita a partir da pesquisa diz respeito à reorganização e ampliação das buscas por tema. Após os relatos, realizamos uma nova catalogação com as palavras indicadas, adicionando-as em mais de um tema para a sua busca. Assim, o exemplo dado de uma palavra que encontrava-se em apenas uma categoria de busca, está disponível em duas abas de temas.

Ainda estamos traçando um começo nos estudos de lexicografia voltados para a Libras. Evidenciamos a necessidade da continuidade de pesquisas e de fomento de ações para a produção de sinais-termos e de iniciativas que valorizem as questões trazidas desde as lutas pelo reconhecimento cultural e linguístico da Comunidade Surda. O aperfeiçoamento do Dicionário é um resultado secundário, que faz parte das próximas etapas de desenvolvimento da ferramenta. Prevemos novas intervenções no contexto educacional estudado.

Desse modo, concluímos que o Dicionário é a implementação de uma PL. Desde que as dificuldades de continuidade dos alunos Surdos na IES foram identificadas, acompanhamos as evasões e as pesquisas deram ênfase às possibilidades de apoiar os processos formativos e de gerar resoluções. Essas, mesmo que mínimas, estavam voltadas para a ideia de que esses alunos Surdos pudessem sentir-se participantes dos esforços no processo de construção dos conhecimentos a partir da elaboração e avaliação da ferramenta e, consequentemente, pertencentes à instituição no ponto de vista identitário. Como a produção deste artigo foi realizada em um momento de pandemia da COVID-19, priorizamos a análise de 
O dicionário como política linguística no contexto do ensino superior Ana Luisa Borba Gediel • Cíntia Kelly Inês Freitas

um material que também possa ser consultado e utilizado de maneira pública e gratuita online.

\section{Referências bibliográficas}

ALONSO, Kátia Mosorov.Tecnologias da Informação e Comunicação e formação de professor: sobre rede e escolas. Educ. Soc., Campinas, vol. 29, n. 104 - Especial, p. 747-768, out. 2008.

BORBA, Francisco da Silva. Organização de dicionário: uma introdução à lexicografia. São Paulo; Ed. UNESP, 2003.

BRASIL. Decreto n. 5.626, de 22 de dezembro de 2005. Regulamenta a Lei no 10.436, de 24 de abril de 2002, que dispõe sobre a Língua Brasileira de Sinais - Libras, e o art. 18 da Lei no 10.098, de 19 de dezembro de 2000. Disponível em: http://www.planalto.gov.br/ccivil_03/_ ato2004-2006/2005/decreto/d5626.htm. Acesso em: 26 mai. 2017.

BRASIL. Decreto n. 6.949, de 25 de agosto de 2009. Promulga a Convenção Internacional sobre os Direitos das Pessoas com Deficiência e seu Protocolo Facultativo, assinados em Nova York, em 30 de março de 2007. Disponível em: http://www.planalto.gov.br/ccivil_03/_ato20072010/2009/decreto/d6949.htm. Acesso em: 26 mai. 2017.

BRASIL. Lei n. 10.436, de 24 de abril de 2002. Dispõe sobre a Língua Brasileira de Sinais Libras e dá outras providências.Disponível em: http://www.planalto.gov.br/ccivil_03/leis/2002/l10436.htm. Acesso em: 26 mai. 2017.

BRASIL. Lei n. 12.711, de 29 de agosto de 2012. Dispõe sobre o ingresso nas universidades federais e nas instituições federais de ensino técnico de nível médio e dá outras providências. Disponível em: http://www.planalto.gov.br/ccivil_03/_ato2011-2014/2012/lei/l12711.htm. Acesso em: 26 mai. 2017.

BRASIL. Lei n. 13.146, de 06 de julho de 2015. Institui a Lei Brasileira de Inclusão da Pessoa com Deficiência (Estatuto da Pessoa com 
O dicionário como política linguística no contexto do ensino superior Ana Luisa Borba Gediel • Cíntia Kelly Inês Freitas

Deficiência). Disponível em: http://www.planalto.gov.br/ccivil_03/_ ato2015-2018/2015/lei/l13146.htm. Acesso em: 26 mai. 2017.

BRASIL. Lei n. 13.409, de 28 de dezembro de 2016. Altera a Lei no 12.711, de 29 de agosto de 2012, para dispor sobre a reserva de vagas para pessoas com deficiência nos cursos técnico de nível médio e superior das instituições federais de ensino. Disponível em:http://www. planalto.gov.br/ccivil_03/_ato2015-2018/2016/lei/L13409.htm. Acesso em: 26 mai. 2017.

BRASIL. Lei n. 9.394, de 20 de dezembro de 1996. Estabelece as diretrizes e bases da educação nacional. Disponível em: http://www.planalto. gov.br/ccivil_03/leis/L9394.htm. Acesso em: 26 mai. 2017.

BRASIL. Parecer CNE/CP 009, de 08 de maio de 2001. Diretrizes Curriculares Nacionais para a Formação de Professores da Educação Básica, em nível superior, curso de licenciatura, de graduação plena. Disponível em: http://portal.mec.gov.br/cne/arquivos/pdf/009.pdf. Acesso em: 26 mai. 2017.

CÁCERES, Glenda Heller. Políticas linguísticas em uma escola pública de ensino médio e tecnológico: a oferta de línguas estrangeiras. Trab.

Ling. Aplic. [online], Campinas, v. 53, n. 1, p. 103-129, jan./jun. 2014. Disponível em:http://www.scielo.br/pdf/tla/v53n1/v53n1a06.pdf. Acesso em: 10 out. 2018

CALVET, Louis-Jean. As políticas linguísticas. Florianópolis e São Paulo: Parábola Editorial/IPOL, 2007. p. 166.

CAPOVILLA, Fernando César. Filosofias educacionais em relação ao surdo: do oralismo à comunicação total ao bilingüismo. In: Revista brasileira de educação especial. São Paulo, v. 6, p. 99-113, 2000.

CARNEIRO, Rodrigo Fernando; PASSOS, Cármen Lúcia Brancaglion. A utilização das Tecnologias da Informação e Comunicação nas aulas de Matemática: Limites e possibilidades. Carneiro RF, Passos CLB. Revista Eletrônica de Educação, v. 8, n. 2, p. 101-119, 2014.

CARDOSO, Vilma Rodrigues. Terminografia da língua brasileira de sinais: glossário de Nutrição. Disponível em: https://repositorio.unb. 
br/bitstream/10482/31522/1/2017_VilmaRodriguesCardoso.pdf. Acesso em 20 out. 2019.

CASTILHO, Ela Wiecko Volkmer. (2006). O papel da escola para a educação inclusiva. Justiça, Cidadania e Democracia. São Paulo: Imprensa Oficial do Estado de São Paulo, 97-106.

DINIZ, Débora; BARBOSA, Lívia; SANTOS, Wederson Rufino dos. Deficiência, direitos humanos e justiça. Revista Internacional de Direitos Humanos - SUR, v. 6, n. 11, p. 65-77, dez. 2009. Disponível em: http://www.scielo.br/pdf/sur/v6n11/04.pdf. Acesso em: 12 de abril de 2018.

DINIZ, Débora. Modelo Social da Deficiência: A Crítica Feminista. Letras Livres. Série Anis 28, Brasília, 1-8, julho, 2003

DINIZ, D. O Que É Deficiência?. São Paulo: Brasiliense, 2007.

FAULSTICH, Enilde; FELTEN, Eduardo Felipe. O signo linguístico e as imagens históricas: a criação de sinais-termos na LSB. Comunicaciones en Humanidades, n. 3, p. 235-245, 2014. Disponível em: http://revistas. umce.cl/index.php/Comunicaciones/article/view/738/720.Acesso em: 22 de mai. 2019.

FAULSTICH, Enilde. Grupo de Estudos Lexicais e Terminológicos. SinalTermo. Nota lexical. Centro Lexterm, Brasília:LIV/UnB/ 2014. Disponível em:http://www.lip.unb.br/nucleos-de-pesquisa/lexterm. Acesso em: 22 de mai. 2019.

FÁVERO, Eugênia Augusta Gonzaga. O direito das pessoas com deficiência à educação. Disponível em: http://egov.ufsc.br/portal/sites/default/files/anexos/15675-15676-1-PB.pdf. Acesso em: 09 nov. 2017.

FLEURI, Reinaldo Matias. Políticas da diferença: para além dos estereótipos na prática educacional. Educ. Soc., Campinas, v. 27, n. 95, maio/ago. 2006. Disponível em: http://www.cedes.unicamp.br. Acesso em: 11 abr. 2017.

GARCIA, Jesus Carlos Delgado; FILHO, Teófilo Alves Galvão. Pesquisa Nacional de Tecnologia Assistiva. São Paulo: ITS BRASIL/MCTI-SECIS, 2012. 68 p. 2013. 
O dicionário como política linguística no contexto do ensino superior Ana Luisa Borba Gediel • Cíntia Kelly Inês Freitas

GATTI, Bernadete Angelina.Grupo focal na pesquisa em ciências sociais e humanas. Brasília: Líber Livro Editora, 2005.

GEDIEL, A. L. B. Falar com as Mãos e Ouvir com os Olhos? A corporificação dos Sinais e os significados dos corpos para os Surdos de Porto Alegre. (Tese de Doutorado em Antropologia Social). Porto Alegre: UFRGS, 2010.

GESSER, Audrei. Libras? Que língua é essa?: crenças e preconceitos em torno da língua de sinais e da realidade surda. São Paulo : Parábola Editorial, 2009.

GIL, Antônio Carlos. Como elaborar projetos de pesquisa. São Paulo: Atlas, 1991, p. 121-125.

GODOY, A. S. Pesquisa Qualitativa - Tipos Fundamentais. 1995. Revista de Administração de Empresas/EAESP/FG, v. 35, n. 3, mai./jun., 1995, p. 20-29.

GUERRA, Míriam Martinez; ANDRADE, Karylleila de Santos. (2012). 0 léxico sob perspectiva: Contribuições da lexicologia para o ensino de línguas. Domínios de Linguagem - Revista Elêtronica de Linguística, 6(1), 226-241.Disponível em: http://www.seer.ufu.br/index.php/dominiosdelinguagem/article/view/14573. Acesso em: 10 de out. 2019.

HONNETH, Axel.Luta por reconhecimento: a gramática moral dos conflitos sociais. São Paulo: Editora 34, 2003.

KARNOPP, Lodenir. Fonética e Fonologia. Florianópolis: UFSC, 2006. [Educação a Distância]. Disponível em: http://www.libras.ufsc.br/colecaoLetrasLibras/eixoFormacaoBasica/foneticaEFonologia/assets/359/ FoneticaFonologia_TextoBase.pdf. Acesso em: 18 jul. 2018.

LACERDA, Cristina Broglia Feitosa de; CAPORALI, Sueli Aparecida; LODI, Ana Claudia. Questões preliminares sobre o ensino de língua de sinais a ouvintes: reflexões sobre a prática. Distúrbios da Comunicação, v. 16(1), p. 53-63, abril. 2004.

MAGNANI, José Guilherme Cantor. "Vai ter música?": para uma antropologia das festas juninas de Surdos na cidade de São Paulo. Revista Ponto Urbe, São Paulo, n.1, p.1-24, 2007. 
MAGNANI. O velho e bom caderno de campo. Revista Sexta Feira, n. 1, p. 8-12, maio 1997.

MATTOS, Carmem Lúcia Guimarães de; CASTRO, Paula Almeida de. (Orgs).Etnografia e educação: conceitos e usos. Campina Grande: EDUEPB, 2011, p. 298.

MEGALE, Antonieta Heyden. Educação bilíngue de línguas de prestígio no Brasil: uma análise dos documentos oficiais. The ESPecialist, v. 39, n. 2, 2018.

MIZRAHI, Saul Eliahú; CICERO, Janete Rocha. A tecnologia assistiva para promoção da aprendizagem e inclusão social do aluno com deficiência. Revista Benjamin Constant, edição especial,p.54-70,2016. Disponível em: http://www.ibc.gov.br/images/conteudo/revistas/benjamin_constant/2016/edicao-especial-05-novembro/bc-ed-especial2016. pdf. Acesso em: 12 abril 2018.

MORAN, José. A integração das tecnologias na educação. In: MORAN, José. A Educação que desejamos: novos desafios e como chegar lá. 5a Ed. Campinas: Papirus, 2013.

MONTEIRO, Myrna Salerno. História dos movimentos dos Surdos e o reconhecimento da Libras no Brasil. In: ETD-Educação Temática Digital 7 (2006), 2, pp. 295-305. Disponível em: https://www.ssoar.info/ ssoar/bitstream/handle/document/10178/ssoar-etd-2006-2-monteiro-historia_dos_movimentos_dos_Surdos.pdf?sequence=1. Acesso em: 10 mai. de 2018.

OLIVEIRA, Roberto Cardoso de. O trabalho do antropólogo: olhar, ouvir, escrever. Revista de Antropologia (USP), vol. 39, n 1, São Paulo, 1996, p.13-37.

PAIVA, Francisco Aulísio dos Santos et al. Um Sistema De Transcrição Para Língua De Sinais Brasileira: O Caso de um Avatar. Revista do GEL, v. 13, p. 12- 48, 2016.

PROMETI, Daniela; COSTA, Messias Ramos; TUXI, Patrícia. Sinal-termo, língua de sinais e glossário bilíngue: atuação da Universidade de Brasília nas pesquisas terminológicas. In: I Congresso Nacional de Libras da Universidade Federal de Uberlândia. 2015. 
QUADROS, Ronice Muller. de. $\mathbf{O}$ bi do bilingüismo na educação de Surdos. In: QUADROS, Ronice Muller. Surdez e bilingüismo. 1 ed. Porto Alegre: Editora Mediação, v.1, p. 26-36. 2005.

QUADROS, Ronice Muller. 0 tradutor e intérprete de língua de sinais e língua portuguesa. Secretaria de Educação de Especial; Programa Nacional de Apoio à Educação de Surdos. Brasília: MEC; SEESP, 2004. QUADROS, Ronice Muller. Educação de Surdos: a aquisição da linguagem. Porto Alegre: Artmed, 1997.

RAJAGOPLAN, Kanavillil. Política linguística: do que se trata, afinal? In: NICOLAIDES, C.; SILVA, K.A.;TILIO,R.;ROCHA,C.H. (Orgs). Política e Políticas Linguísticas. Campinas: Pontes/ALAB, p. 19-42, 2013.

ROCHA, Heloísa Vieira da; BARANAUSKAS, Maria Cecília. Design e Avaliação de Interfaces Humano-Computador. São Paulo: Editora Unicamp, [Capítulo 1: O que é interação/interface humano-computador", p.1-45 e Capítulo 3: "Paradigmas da comunicação humano-computador e design de interfaces", p.101-157]. 2003.

SANTOS, Silvana Aguiar dos. Cad. A implementação do Serviço de Tradução e Interpretação de Libras-Português nas Universidades Federais. Cadernos de Tradução. Florianópolis, v. 35, nºspecial 2, p. 113-148, out. 2015.

SANTOS, Ligia Pereira; PEQUENO, Robson. Novas tecnologias e pessoas com deficiências: a informática na construção da sociedade inclusiva. In. SOUSA, R. P; MOITA, F. M. C S. C; CARVALHO, A. G. (Org.). Tecnologias digitais na educação. Campina Grande: EDUEPB, 2011. Disponível em: http://books.scielo.org/id/6pdyn/pdf/sousa-9788578791247-04.pdf. Acesso em: 12 de abril de 2018.

SANTOS, Nálbia de Araújo. A utilização da técnica de prototipação no desenvolvimento de sistemas de informações contábeis. Research Gate. 2004.

SEVERO, Cristiane Gorski. Política(s) linguística s) e questões de poder. ALFA: Revista de Linguística 57, no. 2. 2013.

SILVA, Julia Izabelle da. $\mathbf{O}$ debate sobre direitos linguísticos e o lugar do linguista na luta dos sujeitos falantes de línguas minorizadas: 